\title{
Changes in the Phenotype of Human Small Cell Lung Cancer Cell Lines after Transfection and Expression of the c-myc Proto-oncogene
}

\author{
Bruce E. Johnson, James Battey, llona Linnoila, Kenneth L. Becker, Robert W. Makuch, Richard H. Snider, \\ Desmond N. Carney, and John D. Minna \\ National Cancer Institute-Navy Medical Oncology Branch and Biostatistics and Data Management Section, National Cancer Institute and \\ Naval Hospital, Bethesda, Maryland 20814; and the Medical Service, Veterans Administration Medical Center, \\ and George Washington University, Washington, DC 20422
}

\begin{abstract}
Small cell lung cancer growing in cell culture possesses biologic properties that allow classification into two categories: classic and variant. Compared with classic small cell lung cancer cell lines, variant lines have altered large cell morphology, shorter doubling times, higher cloning efficiencies in soft agarose, and very low levels of $L$ dopa decarboxylase production and bombesinlike immunoreactivity. C-myc is amplified and expressed in some small cell lung cancer cell lines and all c-myc amplified lines studied to date display the variant phenotype. To investigate if c-myc amplification and expression is responsible for the variant phenotype, a normal human c-myc gene was transfected into a cloned classic small cell lung cancer cell line not amplified for or expressing detectable c-myc messenger RNA (mRNA). Clones were isolated with one to six copies of c-myc stably integrated into DNA that expressed c-myc mRNA. In addition, one clone with an integrated neo gene but a deleted $c-m y c$ gene was isolated and in this case c-myc was not expressed. $\mathrm{C}$-myc expression in transfected clones was associated with altered large cell morphology, a shorter doubling time, and increased cloning efficiency, but no difference in $\mathrm{L}$ dopa decarboxylase levels and bombesinlike immunoreactivity. We conclude increased c-myc expression observed here in transfected clones correlates with some of the phenotypic properties distinguishing c-myc amplified variants from unamplified classic small cell lung cancer lines.
\end{abstract}

\section{Introduction}

Some previously identified biologic activities of the c-myc gene in mammalian cells include the ability to immortalize rat fibroblast cells (1) and to cooperate with ras-like oncogenes to induce tumorigenic conversion of primary rat embryo fibroblast cells (2). In addition, c-myc gene expression appears to stimulate transfected rat fibroblasts to form tumors in nude mice and syngeneic rats (3) and is associated with breast cancer in transgenic mice (4). Further, c-myc expression is induced by a wide variety of mitogens including serum (5), platelet derived growth factor, fibroblast growth factor (FGF), epidermal growth factor (EGF) $(6-8)$, and partial hepatectomy $(9,10)$. Increased c-myc expression in transfected cell lines is also associated with a higher cloning efficiency in soft agar and a more rapid growth rate of rat fibroblast cells in low serum conditions $(1,3)$.

Address reprint requests to Dr. Johnson, NCI-Navy Medical Oncology Branch, Building 8, Room 5108, Naval Hospital, Bethesda, MD 20817.

Received for publication 4 November 1985 and in revised form 11 March 1986.

The Journal of Clinical Investigation, Inc.

Volume 78, August 1986, 525-532
Small cell lung cancer (SCLC) ${ }^{1}$ cells offer another opportunity for studying the biologic role of c-myc. The variant subset of SCLC cell lines has a four- to 60-fold DNA amplification of c$m y c$ and shows high expression of this gene $(11,12)$. In addition, a large amount of immunoreactive c-myc protein has been demonstrated in a c-myc amplified variant SCLC cell line, N417 (13). Compared with the more common classic SCLC lines, which do not express c-myc, variant cell lines have altered morphology in cell culture (growth in loose chains), altered athymic nude mouse xenotransplant histology (large cells with abundant cytoplasm and prominent nucleoli), and different biochemical properties from classic SCLC. The variants produce low or undetectable levels of $\mathrm{L}$ dopa decarboxylase, a marker of neuroendocrine differentiation. They also produce low or undetectable levels of bombesin-like immunoreactivity (gastrin releasing peptide), a putative autocrine growth factor in small cell lung cancer (14). The SCLC variants also have a more rapid doubling time, a 10-fold higher soft agarose cloning efficiency, and are less radiosensitive (15-17). Thus, the two types of cell lines derived from different patients with the same malignancy have easily evaluable phenotypic differences and the more aggressive variant phenotype is closely associated with c-myc amplification and expression.

Although a close association with the more aggressive variant phenotype of SCLC cell lines has been demonstrated, the causal role for $c-m y c$ in generating the variant phenotypic has not been proven. The recent development of electroporation (18-20) for introducing DNA into cells growing in suspension has allowed us to introduce a normal human c-myc gene covalently linked to the neomycin resistance gene, aminoglycoside $3^{\prime}$ phosphotransferase (neo), into a classic SCLC cell line. Transformants expressing the transfected DNA can then be selected using the aminoglycoside antibiotic G-418. Thus, we are able to ask if c$m y c$ could be expressed and affect the phenotype of a classic SCLC cell line and compare the transformants to amplified variant SCLC cell lines.

\section{Methods}

Cell lines and cell culture. Three SCLC cell lines, H209, H146, and N417, representing cell lines with different levels of c-myc mRNA expression, were used as controls and have been characterized as previously described $(11,15,16)$. H209 is a classic SCLC cell line that does not express detectable c-myc mRNA. $\mathrm{H} 146$ has properties intermediate between a classic and a variant and expresses c-myc mRNA at levels intermediate between $\mathrm{H} 209$ (classic) and $\mathrm{N} 417$ (variant). $\mathrm{N} 417$ is variant SCLC cell line amplified 50-fold for c-myc and expressing abundant

1. Abbreviations used in this paper: FCS, fetal calf serum; kb, kilobase; SCLC, small cell lung cancer. 
amounts of c-myc mRNA. The cell line $\mathrm{H} 209$ was cloned in soft agarose and one of the clones, DD1, was used for the electroporation. The cells were grown under standard conditions $(15,16)$.

Electroporation. A c-myc-neo plasmid was constructed by inserting a 12.7 Eco RI human c-myc gene cloned from the leukocytes of a normal volunteer into the Eco RI site of pBR 327. In addition, a 3.4-kilobase (kb) Bam HI neo gene was constructed by ligating Bam HI linkers to the Pvu II site of the Pvu II-Bam HI fragment containing the SV 40 promoter and neomycin resistance gene from pSV2 neo plasmid. This Bam HI fragment was inserted into the Bam HI site of the pBR 327-myc plasmid. This plasmid was linearized with Pvu I and electroporated with $5 \times 10^{6}$ cells from cloned cell line $\mathrm{H} 209 \mathrm{DD} 1$ at $2 \mathrm{KV}$ at $0^{\circ} \mathrm{C} \mathrm{(18)}$. After electroporation, the cells were resuspended at $1 \times 10^{6} \mathrm{cells} / \mathrm{ml}$ in $10 \%$ fetal calf serum (FCS)-RPMI 1640 for 1 wk, and were then selected at 800 $\mu \mathrm{g} / \mathrm{ml}$ of G-418 (real concentration, $370 \mu \mathrm{g} / \mathrm{ml}$ ). $5 \times 10^{4}$ cells were placed in each well of a 96-well microtiter dish and 35 clones were isolated.

Preparation of DNA and RNA. Cells were grown to a density of 2$5 \times 10^{6}$ cells $/ \mathrm{ml}$ in log phase culture. Total cellular RNA and DNA was prepared from the same cells as described by Chirgwin (21) and Hieter (22).

Southern, Northern, and $S_{1}$ nuclease analysis. Southern blots were prepared, hybridized, washed, and exposed as described by Southern (23) and Little (11). Northern blots were prepared, hybridized, washed, and exposed on radiographs as described by Little (11). The DNA restriction fragments labeled by nick translation were an Rsa 1-Xba 1 fragment containing the first exon (first exon probe), an Eco RI-Cla 1 fragment containing the third exon (third exon probe), and a Bam HIBam HI fragment containing the neomycin gene (neo probe). The same Northern blot was washed at $70^{\circ} \mathrm{C}$ and rehybridized to a human beta actin probe to control for the amount of mRNA (24). $S_{1}$ nuclease studies were carried out as described by Battey (25). A Pvu II-Pvu II fragment containing the $5^{\prime}$ promoter region of the first exon (promoter region probe) was used for the $S_{1}$ studies.

Soft agarose cloning and doubling times. Cells growing in log phase were made into a single cell suspension plated in $0.3 \%$ agarose to yield 30-1,000 colonies per $40-\mathrm{mm}$ dish. The colonies of $>50$ cells were counted at 2-3 wk. Each doubling time was determined by plating 2.5 $\times 10^{4}$ cells $/ \mathrm{ml}$ in $2 \mathrm{ml}$ of RPMI plus $10 \%$ FCS in 24-well macrotiter dishes (Gibco, Long Island, NY) and counting the cells in duplicate from two wells every $2 \mathrm{~d}$. One-fourth to one-half of the medium was replaced every $2 \mathrm{~d}$. The doubling times for each replicate were then determined independently by a biostatistician (Robert W. Makuch) using a standard approach $(26,27)$.

Cell culture morphology and nude mouse histology. The cell culture photographs were taken of cell lines and transfected clones growing in log phase growth in $10 \%$ FCS-RPMI $16402 \mathrm{~d}$ after feeding. $2 \times 10^{7}$ cells were injected subcutaneously into nude mice. The tumors were harvested simultaneously at 6-12 wk, fixed in formalin, embedded in paraffin, and typical sections were stained with hematoxylin and eosin. The histologic sections were examined and photographed by a pathologist unaware of the origin of the tissue.

Dopa decarboxylase and bombesin-like immunoreactivity. $\mathrm{L}$ dopa decarboxylase production was determined as previously described (28) and bombesin-like immunoreactivity was determined as previously described (29).

\section{Results}

Neo gene integration and expression. The cloned cell line, NCI H209 DD1, possesses all previously described properties of a classic SCLC cell line and does not express detectable c-myc mRNA. The c-myc-neo plasmid (Fig. 1) was linearized by cleavage in vector sequences with Pvu I and transfected into H209 DD1 using electroporation. 35 independent clones were selected using the aminoglycoside antibiotic G-418. DNA from all selected clones studied contained at least one copy of the neomycin

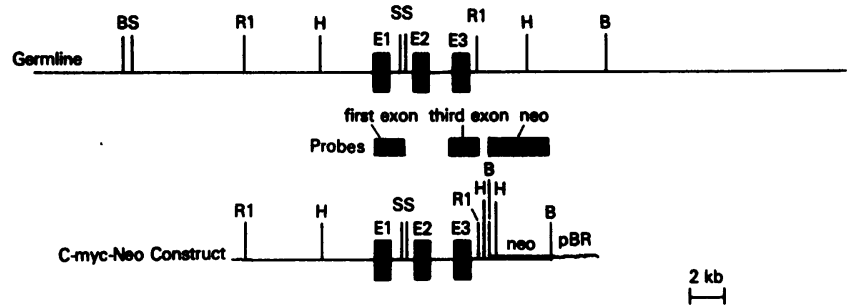

Figure 1. Restriction endonuclease maps of the c-myc and the c-mycneo construct. This is a schematic representation of the germ-line human c-myc locus and the c-myc-neo construct. The solid boxes numbered E1-E3 denote the exons of c-myc. The solid bar in the c-mycneo construct labeled neo denotes the 3.4-kb neo gene described in Methods. The wavy line labeled pBR represents pBR 327 sequences. The solid bars between the two schematic representations labeled the first exon, third exon, and neo probes represent DNA fragments subsequently used for hybridizations and are described in Methods. The partial restriction map is shown in schematic representation of the c$m y c$ germline locus and the c-myc-neo construct, with the following cleavage sites: B, Bam HI; S, Sst I; RI, Eco RI; and H, Hind III.

resistance gene. The clones had a spectrum of in vitro morphologies and five (identified as clones A, B, C, D, and E) were selected for further study. The clones were compared to three nontransfected small cell lung cancer cell lines expressing different amounts of c-myc mRNA (H209, H146, and N417).

We first tested for integration of the c-myc-neo construct into H209 genomic DNA (Fig. 2). As expected, the three untransfected control SCLC cell lines (H209, H146, and N417) have no evidence of the neo gene. In contrast, the five transfected clones each contain a 3.4-kb Bam HI fragment with an intact neo gene fragment. In addition, clone $\mathrm{C}$ and $\mathrm{E}$ have additional bands after Bam HI digestion which may represent a deletion or rearrangement of a portion of the 3.4-kb Bam $\mathrm{HI}$ neo fragment. All five transfected clones have the $0.7-\mathrm{kb}$ Hind III fragment containing the SV 40 promoter and enhancer region necessary for neo expression in mammalian cells (Fig. 2). Another Hind III DNA fragment hybridizing to the neo probe is generated when Hind III cuts once in the neo gene and the second site is donated by the next Hind III site available in the flanking host genome. These larger Hind III fragments are different sizes in all five transfected clones, which indicates the integration occurred at different sites. They also allow estimation of the number of copies of the neo gene integrated into the host genome. Clone $A, B$, and D each have one copy, clone $C$ has two copies, and clone $\mathrm{E}$ has six copies and the different sizes of neo fragments generated by Hind III digestion suggest the transfected gene integration into the host genome is unlinked and is probably random. Finally, as expected, Northern blot analysis shows no evidence of neo expression in the parent host cell line, H209, while 1.4-kb neo mRNA is present in all five transfected clonal derivatives of $\mathrm{H} 209$ growing in selective medium containing the aminoglycoside antibiotic, G-418.

$C$-myc gene integration. To determine the number of c-myc genes introduced by transfection, three nontransfected control cell lines and five transfected clones were hybridized to the third and first exon probes after various restriction enzyme digestions (Fig. 3). The first two lanes show the parental untransfected cell line, H209, and H146 genomic DNA digested with Eco RI. Neither cell line has c-myc gene amplification. The third lane shows N417 which is highly amplified for c-myc genes as has been 

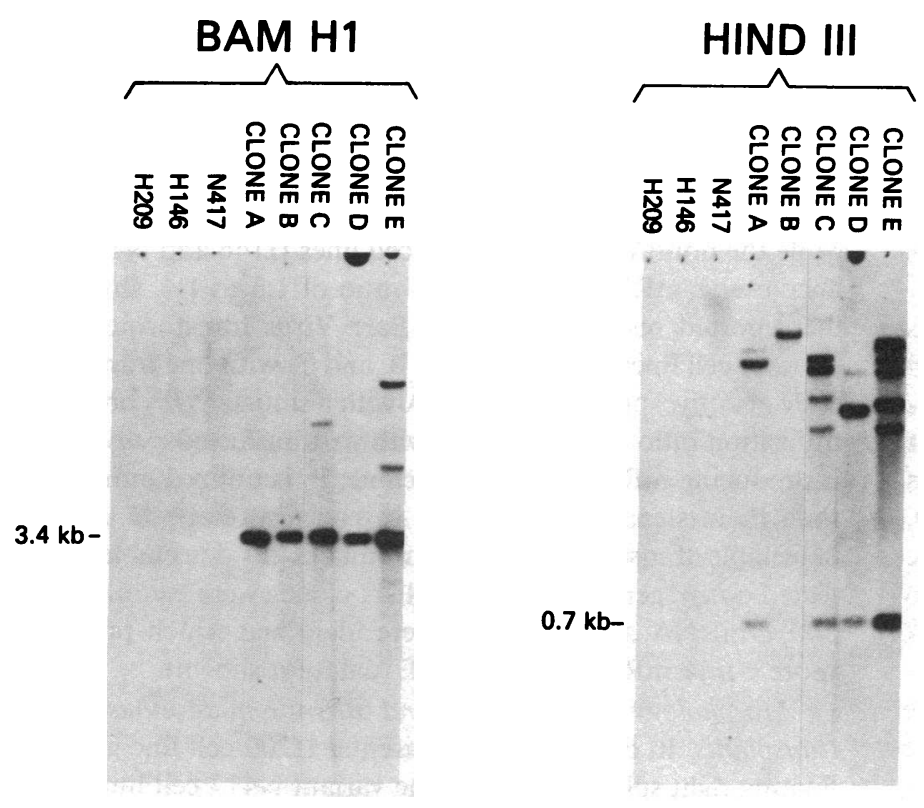

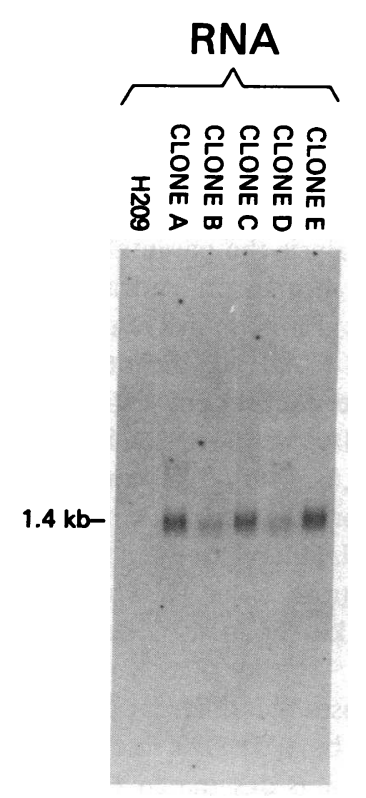

Figure 2. Neo gene integrations and expression. In the first two panels, $10 \mu \mathrm{g}$ of DNA from three control SCLC cell lines and five transfected clones was digested with the designated restriction endonucleases, electrophoresed in $\mathbf{0 . 8 \%}$ agarose gels, transferred to nitrocellulose paper, and hybridized with ${ }^{32} \mathrm{P}$-labeled neo fragment. The third panel represents $10 \mu \mathrm{g}$ of total cellular RNA isolated from the host $\mathrm{H} 209$ and five transfected clones growing in log phase, electrophoresed in a $0.8 \%$ agarose formaldehyde gel, blotted to nitrocellulose, and hybridized with ${ }^{32}$ P-labeled DNA (neo probe in Fig. 1). previously described (11). Genomic DNA from clones A, C, and $E$ digested with Eco RI give fragments other than the $12.7 \mathrm{~kb} \mathrm{c}$ $m y c$ insert in the c-myc-neo construct. It appears the transfected $12.7 \mathrm{~kb}$ c-myc sequence from the plasmid is rearranged or deleted during transfection and subsequent integration in clones $\mathrm{A}, \mathrm{C}$, and multiple times in clone $\mathrm{E}$. The rearrangement or deletion appears to include sequences $5^{\prime}$ to the c-myc gene because the c-myc-neo Hind III site $27 \mathrm{bp}$ from the Eco RI site immediately flanking the third c-myc exon is retained in all five clones (Fig. 2, Hind III digest). The DNA from the five transfected clonal derivatives of $\mathrm{H} 209$ was hybridized to the most $5^{\prime} \mathrm{c}-m y c$ fragment in the construct, a 1.1-kb Eco RI-Bgl II fragment. Three of the additional bands from clone $\mathrm{E}$ were not seen, showing that in at least some cases the $5^{\prime} \mathrm{c}-m y c$ flanking sequences furthest from the gene are deleted from the construct integrated into the host DNA (data not shown).
The parental cell line, $\mathrm{H} 209$, and all five transfected clones retain the 11.4-kb Hind III germ line c-myc fragment (Fig. 3, panel 2). In addition, clones $\mathrm{A}, \mathrm{B}, \mathrm{C}$, and $\mathrm{E}$ have new bands at $8.8 \mathrm{~kb}$, the predicted size of a Hind III c- $m y c$ fragment from the c-myc-neo construct (Fig. 1). Clone $\mathrm{D}$ is missing this novel sized Hind III band despite the presence of a neo gene (Fig. 2). Parental $\mathrm{H} 209$ and all five clones show the germ line 23-kb Bam HI fragment containing the third exon of c-myc (Fig. 3, panel 3). In addition, clones $\mathrm{A}, \mathrm{B}, \mathrm{C}$, and $\mathrm{E}$ show differently sized bands. The Bam HI cleaves once in the c-myc-neo construct at the $5^{\prime}$ origin of the neo gene and once at the next flanking genomic Bam HI site $5^{\prime}$ to the integrated portion of c-myc-neo construct. Clone $\mathrm{D}$ again shows no evidence of a novel third exon hybridizing fragment from the c-myc-neo construct. The germ line $14.7 \mathrm{~kb}$ Sst I fragment containing the first exon is seen in the H209 parental cell line and all five clones (Fig. 3, panel 4). In

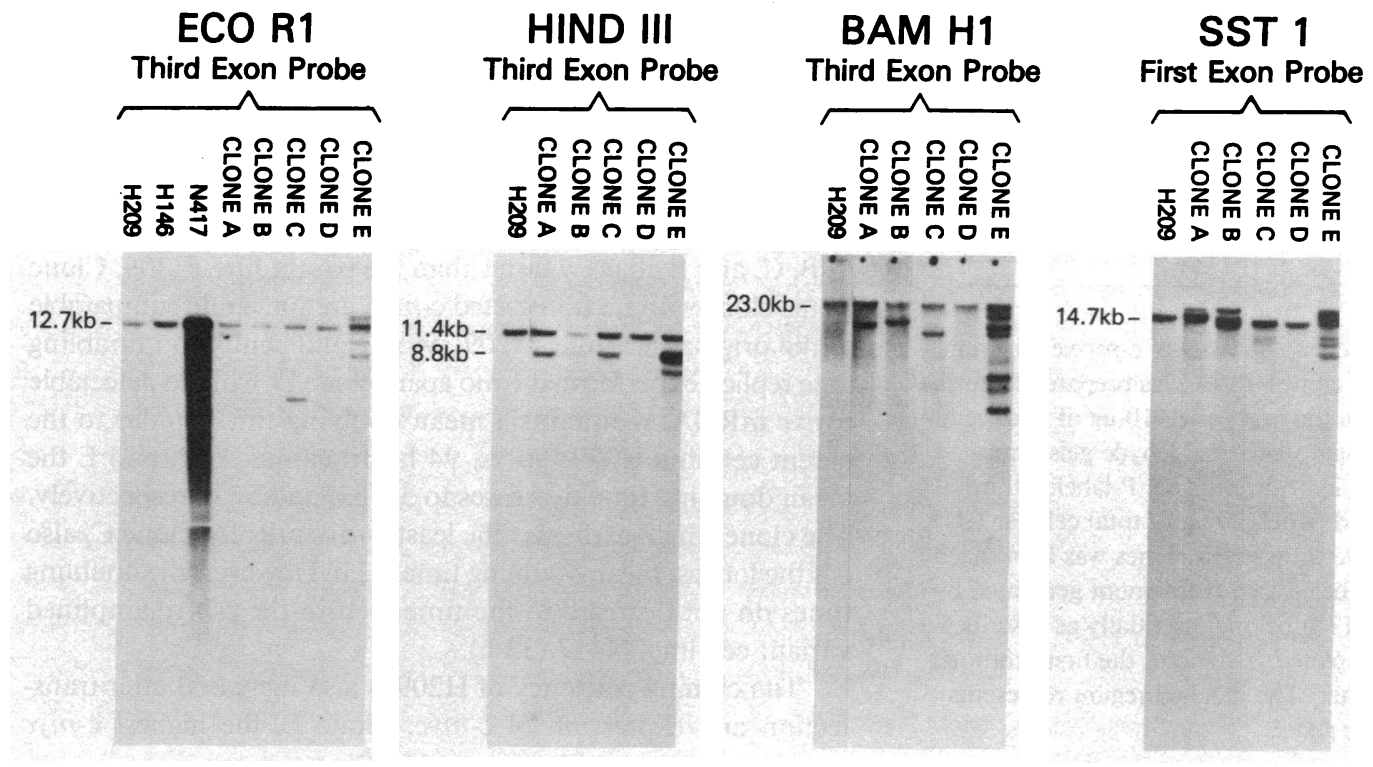

Figure 3. Southern analysis of DNA from three control SCLC cell lines and five clones transfected with c$m y c$. DNA was prepared from cell lines and clones growing in log phase. $10 \mu \mathrm{g}$ was digested with restriction endonucleases, electrophoresed in $0.8 \%$ agarose, transferred to nitrocellulose paper, and hybridized to two different ${ }^{32} \mathrm{P}$-labeled fragments. The third exon and first exon probes of c-myc are described in Methods. A partial restriction map is shown in schematic representation of the c-myc germline locus and the $c$ myc-neo construct in Fig. 1. 
addition, multiple sized fragments from the c-myc-neo construct are seen hybridizing to a c-myc exon 1 probe in clones $\mathrm{A}, \mathrm{B}, \mathrm{C}$, and $\mathrm{E}$. No exogenous $\mathrm{c}-m y c$ first exon is seen in clone $\mathrm{D}$.

Expression of transfected c-myc genes. C-myc expression in the three nontransfected control cell lines, H209, H146, and N417, and five $\mathrm{H} 209$ derived transfected clones differ markedly (Fig. 4). By Northern blot analysis the parental cell line H209 expresses no detectable c-myc mRNA. In contrast, N417 is amplified for c-myc and produces abundant mRNA. Cell line H146 is not amplified for c-myc but makes significant levels of c-myc mRNA (Fig. 4). Dilution experiments demonstrate $\mathrm{H} 209$ is expressing $<1 / 20$ of the mRNA produced by $\mathrm{H} 146$ (data not shown). Transfected clones $\mathrm{A}, \mathrm{B}, \mathrm{C}$, and $\mathrm{E}$ all contain exogenous $c-m y c$ DNA and all make normal size c-myc mRNA (2.3 kb). Clone $E$ produces more $m R N A$ than clone $A$ and $B$ while clone $C$ produces the least. In contrast, clone $D$, which contains no exogenous c-myc DNA, makes no detectable c-myc mRNA (Fig. 4).

The human c-myc gene uses two different promoters in the first exon separated by $170 \mathrm{bp}$ (25). The more $5^{\prime}$ of these is designated $P_{1}$ and the more $3^{\prime}$ is designated $P_{2}$. We therefore

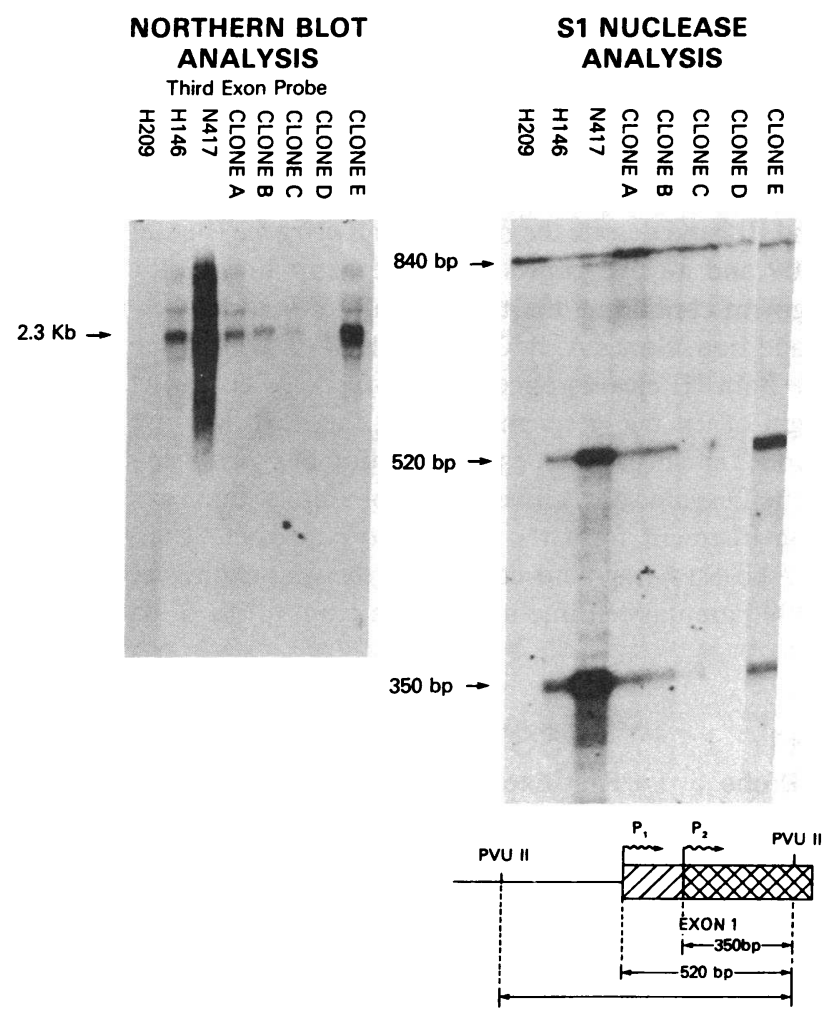

Figure 4. Northern blot and $S_{1}$ nuclease analysis of c-myc expression of SCLC cell lines and transfected clones. RNA was prepared from the cell lines and transfected clones. In the first panel, $10 \mu \mathrm{g}$ of total cellular RNA was electrophoresed on agarose-formaldehyde gels, transferred to nitrocellulose paper, and hybridized to a ${ }^{32} \mathrm{P}$-labeled third exon probe of c-myc. In the second panel, $20 \mu \mathrm{g}$ of total cellular RNA from three SCLC cell lines and five transfected clones was hybridized with a 0.84-kb single strand ${ }^{32} \mathrm{P}$-labeled Pvu II fragment generated by primer extension of an exon $1 \mathrm{M} 13$ subclone essentially as described by Battey (25). Under the second panel, $P_{1}$ denotes the first promoter and $P_{2}$ denotes the second promoter. The hatched region represents the first exon of the human c-myc gene. performed $S_{1}$ nuclease protection studies of c-myc mRNA using a promoter region probe $(0.84 \mathrm{~kb}$ Pvu II-Pvu II fragment, Fig. 4). Using this probe, $P_{1}$-initiated transcripts yield a 520 base $S_{1}$ protected transcript, while $\mathrm{P}_{2}$-initiated transcripts generate a 350 base protected species (Fig. 4, second panel). The parental H209 cell line was again seen not to produce detectable c-myc mRNA while the nontransfected control cell lines $\mathrm{H} 146$ and N417 produce c-myc mRNA with a $P_{1} / P_{2}$ ratio of $1: 3$ to $1: 4$, similar to the reported results for Epstein-Barr Virus transformed lymphocyte cell lines (12). Clones A, B, and C, with one transfected copy of c-myc, produce an mRNA with a similar $\mathrm{P}_{1} / \mathrm{P}_{2}$ promotor utilization ratio of $1: 3$. Clone $\mathrm{E}$ with six transfected $\mathrm{c}-m y c$ genes is producing mRNA, but in this clone, $P_{1}$ is utilized more often than $P_{2}$ in steady state mRNA. In contrast, clone $D$ with no detectable transfected $c-m y c$ gene makes no detectable transfected c-myc gene. An additional six clones were examined for c-myc mRNA and no clones were identified which produced more c-myc mRNA than clone E (data not shown).

Morphology in cell culture and athymic nude mouse xenotransplants. In cell culture the parental $\mathrm{H} 209$ cell line grows in floating tight spheres (Fig. 5). The variant N417 cell line shows larger cells that grow in a very linear pattern. Clone $\mathrm{E}$ has larger cells and is growing in a more linear and open morphology than $\mathrm{H} 209$, resembling a variant pattern in cell culture.

The classic SCLC cell line $\mathrm{H} 209$ forms tumors in nude mice composed of small monotonous cells and very few mitotic figures (Fig. 6). The histology of N417 in nude mice has enlarged cells with prominent nucleoli and more mitotic figures. Clone $\mathrm{E}$ has histologic features between $\mathrm{H} 209$ and the variant, N417. Clone E cells are larger with more prominent nucleoli and mitotic figures than $\mathrm{H} 209$ cells. DNA was extracted from an athymic nude mouse xenograft of clone E, digested with Bam HI, and hybridized with the third exon c-myc fragment. Six single copies of $c-m y c$ in the same pattern as the original clone growing in cell culture were demonstrated (data not shown). Therefore, additional c-myc amplification or rearrangement in the nude mouse tumor did not account for the change in morphology. Thus, the transfected H209 clones expressing c-myc appear to have developed some but not all of the morphologic and histologic changes associated with the variant phenotype.

Doubling time and cloning efficiency analysis. The doubling time was inversely related to the steady state level of c-myc mRNA in the control cell lines, H209, H146, and N417 (Table I). The c-myc mRNA signal on autoradiographs was quantitated by densitometry and the amount of c-myc mRNA in each lane was standardized using a beta actin mRNA signal as a reference control. The cell growth curves of the c-myc transfected clones grew more rapidly than the parent line, H209 (Table I). Clones A, B, C, and E all grew faster than the parent line, H209. Clone $\mathrm{D}$, the clone with no transfected c-myc, grew at a rate comparable to the original cell line, H209. Most significantly, on doubling time replicates performed 1 mo apart, clone $D$, with no detectable c-myc mRNA, maintains a mean doubling time similar to the parent cell line $\mathrm{H} 209$ (90 vs. 94 h). In clones A, B, and E the mean doubling time decreases to 54,51 , and $57 \mathrm{~h}$, respectively. The clone which expresses the least c-myc mRNA, clone $\mathrm{C}$, also has the longest mean doubling time, $62 \mathrm{~h}$. However, the doubling times do not decrease to the time seen in the c-myc amplified variant cell line, $\mathrm{N} 417$ (33 h).

The cloning efficiency of $\mathrm{H} 209$ is also increased after transfection and expression of c-myc. Clone $\mathrm{E}$, the highest c-myc 


\section{H2O9}

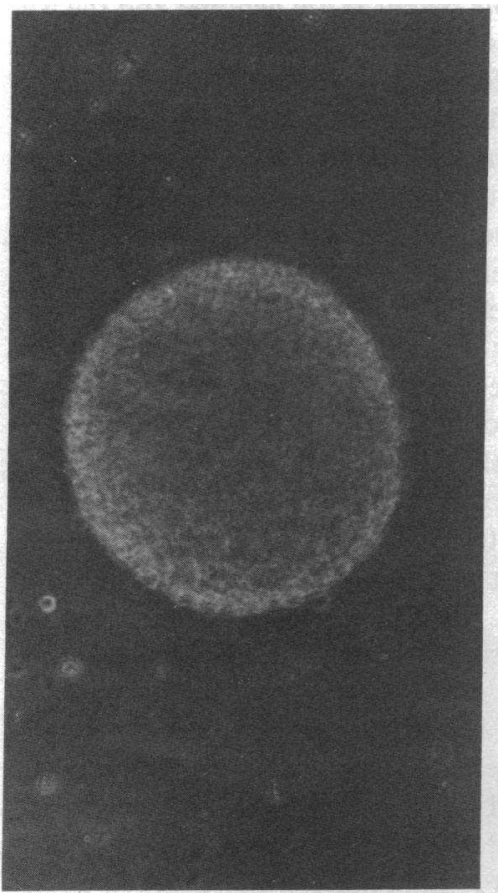

H2O9 CLONE E

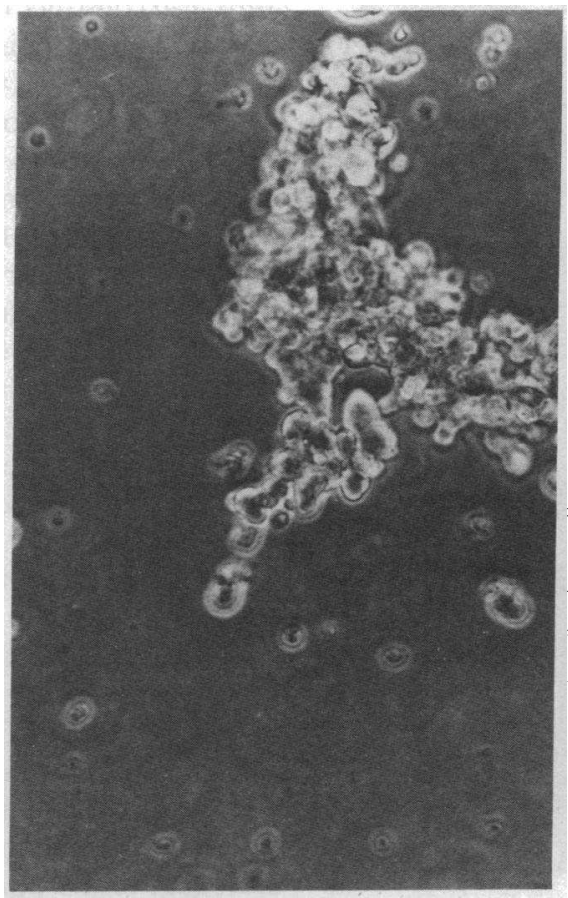

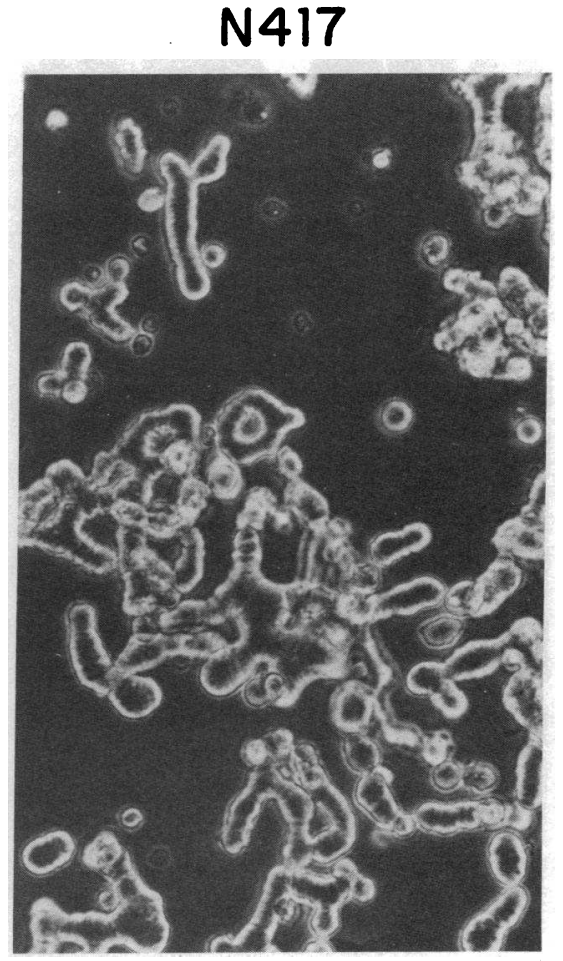

Figure 5. Cellular morphology of SCLC cell lines and a transfected clone. Cells growing in log phase in RPMI plus 10\% FCS were spit 1:4 $4 \mathrm{~d}$ before being photographed. New medium was added $2 \mathrm{~d}$ before, and the cells were photographed using a phase construct Nikon photo microscope. Magnification, $\times 100$.

producing transfected clone, has a 5-10-fold increase in cloning efficiency over its parent $\mathrm{H} 209$ and resembles that of $\mathrm{H} 146$, correlating with the comparable levels of c-myc mRNA in these two cell lines. The cloning efficiency of clone $A$ and $D$ resembled that of the parent line H209. Although c-myc mRNA was present in clone $\mathrm{A}$ and the doubling time was shortened, no difference in the cloning efficiency was observed compared with the parental line H209. Possible explanations are that an early observed effect with increased c-myc mRNA is more rapid growth, but a higher level of c-myc mRNA expression is needed to observe an increase in cloning efficiency, or additional unidentified factors other than c-myc are present in $\mathrm{H} 146$ which increase the cloning efficiency.

Biochemical properties. The parent line, H209, produces large amounts of bombesin-like immunoreactivity (Table I). Both c-myc producing control SCLC lines, H146 and N417, yield very low levels of bombesin-like immunoreactivity (gastrin releasing peptide). Bombesin is produced in all five transfected clones at levels comparable to or greater than the parent cell line H209. L dopa decarboxylase, a marker of neuroendocrine differentiation, is produced in the control cell lines, H209 and H146, but not in the variant, N417 (Table I). L dopa decarboxylase continued to be produced in all five transfected clones.

\section{Discussion}

The small cell lung cancer system offers an opportunity for studying the role of c-myc in human malignancy. We have demonstrated that electroporation can introduce an exogenous nor- mal human c-myc gene into a typical classic SCLC cell line, H209, and that c-myc mRNA can now be expressed. The clone producing the highest amount of steady state c-myc mRNA, clone $\mathrm{E}$, shows properties analogous to the variant type of SCLC associated with c-myc amplification and expression (15). The morphology in cell culture became more open and linear, the atymic nude mice xenotransplants developed larger cells with prominent nucleoli, the doubling time shortened, and the cloning efficiency increased. However, the bombesin-like immunoreactivity and $\mathrm{L}$ dopa decarboxylase production did not markedly decrease.

Classic SCLC cells are unusual because the cell lines examined with the exception of $\mathrm{H} 146$ have no detectable c-myc mRNA expression $(11,12)$. It appears that this decreased expression is not associated with a translational increase in c-myc protein because no immunoreactive c-myc protein is detected in another classic SCLC line, H128 (13).

The classic SCLC cell line H209 expresses no detectable c-myc mRNA. When the normal c-myc gene is introduced by electroporation into the host genome, the clones produce detectable c-myc mRNA. The absence of c-myc mRNA in this SCLC cell line does not appear to be an unusual genetic property of the person from whom the cell line is derived. The EpsteinBarr Virus transformed lymphoblastoid cell line, H209BL, started from the same individual, produces detectable c-myc mRNA (data not shown). We cannot formally prove the exogenous c-myc gene is responsible for the expressed c-myc mRNA. However, the evidence of the increased c-myc steady state mRNA with increased c-myc copy number in clone $\mathrm{E}$ and nondetectable 

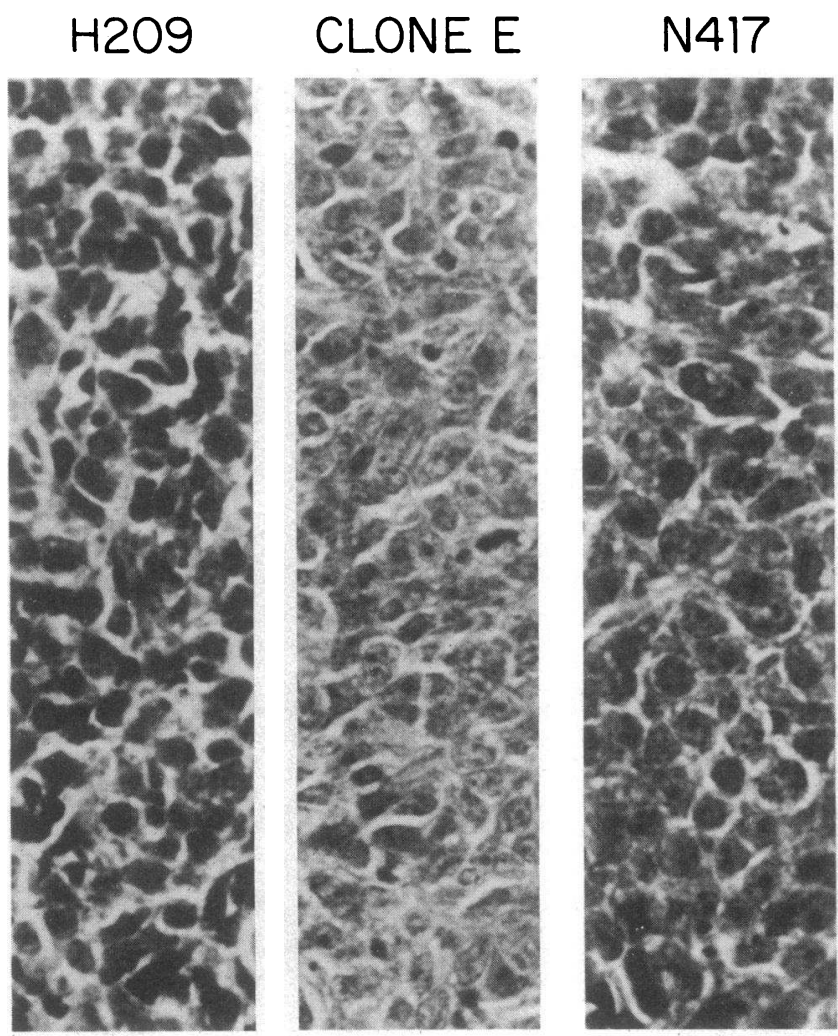

Figure 6. Histology of athymic nude mouse xenotransplants of SCLC cell lines and a transfected clone. $\sim 2 \times 10^{7}$ cells growing in log phase were injected subcutaneously into athymic nude mice. The tumors were harvested simultaneously, fixed in formalin, embedded in paraffin, and routine sections stained with hemotoxylin and eosin. Magnifcation, $\times 550$.

c- $m y c$ mRNA in clone D when the first and third exon are deleted, strongly suggests the exogenous c-myc genes are responsible for the observed increase in c-myc mRNA. This expression of c-myc in transfected SCLC lines bears some resemblance to Burkitts lymphoma where the c-myc gene is moved to the immu- noglobulin locus and the translocated gene is nearly always expressed while the germline gene is inactive (30-33). However, the contribution of the apparent random integration of the c-myc-neo construct into the parent $\mathrm{H} 209$ genome and the SV 40 enhancer present in the c-myc-neo construct to the increased c-myc mRNA in the transfected clones is not yet determined.

The Southern blot analysis of the transfected clones shows that the 12.7-kb Eco RI fragment containing the three coding exons of c-myc does not usually remain intact after transfection (Fig. 2, first panel). However, the 8.8-kb Hind III fragment derived from the construct remains intact in all the clones except for the single band from clone E. (Fig. 2, second panel). It is interesting to observe that all the areas of the human c-myc locus which cross-hybridize with the mouse c-myc locus are contained in this Hind III-Eco RI fragment (25). The deletion of the most $5^{\prime}$ sequences of the $12.7 \mathrm{~kb}$ Eco RI c-myc fragment and the loss of the coding exons of c-myc in clone $E$ suggest that the $c-m y c$ gene may be altered during electroporation; during integration into the host genome, or may be deleted after integration.

The $S_{1}$ nuclease analysis also shows that the promoter utilization of the c-myc gene in SCLC can be altered after transfection. In the SCLC cell lines producing c-myc mRNA, the 1:3 $P_{1} / P_{2}$ promoter ratio seen in Epstein-Barr Virus transformed lymphocytes is maintained $(12,33)$. In the transfected cell line clone $E$ switches to make $P_{1}$ the predominant promoter. This is analogous to the Burkitt's lymphoma cell lines, BL16, BL22, BL31, and BL37, where all three coding exons of $\mathrm{c}-m y c$ remain together after rearrangement and the $P_{1} / P_{2}$ ratio changes to approximately equimolar $(33,34)$. Thus, in both these systems when all three exons of $c-m y c$ are introduced into a new chromosomal environment, the promoter ratio is changed despite the three-exon structure of the gene remaining intact.

Morphologic changes and alterations in growth properties with myc transfection have been observed in other systems. NIH/ 3T3, Rat-2 (3), and avian embryonic fibroblasts (35) change morphology after transfection with c-myc or v-myc. In addition, more rapid growth in low serum and higher cloning efficiencies are seen with rat-2 and NIH/3T3 cells after transfection with cmyc (3).

Table I. Growth and Biochemical Characteristics of Control Cell Lines and Transfected Clones

\begin{tabular}{|c|c|c|c|c|c|c|c|c|}
\hline & $\mathrm{H} 209$ & H146 & N417 & Clone A & Clone B & Clone C & Clone D & Clone $\mathbf{E}$ \\
\hline $\begin{array}{l}\text { Relative c-myc mRNA } \\
\text { (Arbitrary units*) }\end{array}$ & $<0.05$ & 1.5 & 65 & 1 & 1 & 0.25 & $<0.05$ & 3 \\
\hline \multicolumn{9}{|l|}{ Doubling time $(h)$} \\
\hline Replicate 1 & 92 & 44 & 35 & 55 & 45 & 54 & 90 & 57 \\
\hline Replicate 2 & 96 & 44 & 32 & 52 & 56 & 69 & 90 & 56 \\
\hline \multicolumn{9}{|l|}{ Cloning efficiency } \\
\hline $\begin{array}{l}\text { Mean percent } \\
\text { (SE) }\end{array}$ & $\begin{array}{l}0.3 \\
(0.04)\end{array}$ & $\begin{array}{l}2.0 \\
(0.1)\end{array}$ & $\begin{array}{c}7.4 \\
(0.2)\end{array}$ & $\begin{array}{l}0.2 \\
(0.02)\end{array}$ & Not done & Not done & $\begin{array}{l}0.2 \\
(0.06)\end{array}$ & $\begin{array}{l}1.5 \\
(0.1)\end{array}$ \\
\hline Bombesin-like immunoreactivity & 5.5 & 0.1 & $<0.01$ & 18 & 6.0 & 9.3 & 5.5 & 5.5 \\
\hline L dopa decarboxylase activity§ & 55 & 116 & 0.4 & 50 & 85 & 57 & 55 & 37 \\
\hline
\end{tabular}

* Arbitrary units were determined by densitometry tracings of autoradiograms (exposed in the linear range) normalized to the amount of beta actin mRNA detected on the same blot. Equivalent relative values are obtained if the c-myc signal is normalized to the amount of mRNA added to each lane. $\ddagger$ Picomoles/milligram of protein (pm/mg protein). $§$ Nanomoles of carbon dioxide/milligram of protein $(\mathrm{nm} \mathrm{CO} / \mathrm{mg} \mathrm{protein)}$. 
Variant SCLC cell lines have markedly decreased or absent bombesin-like immunoreactivity and have decreased production of one of the neuroendocrine markers, $L$ dopa decarboxylase. At the level of c-myc expression in the transfected clones, the biochemical markers, bombesin-like immunoreactivity and Ldopa decarboxylase, are not markedly different from those of the original clone. The steady state level of c-myc mRNA in the transfectants is at least 10 -fold below the variant N417. This may explain the observation that the L dopa decarboxylase activity does not decrease to the level of the variant, N417 (Table I), if high levels of c-myc mRNA are needed to suppress $\mathrm{L}$ dopa decarboxylase activity. However, some of the transfectants produce steady state c-myc mRNA comparable to the control cell line $\mathrm{H} 146$ where bombesin-like immunoreactivity is decreased (Table I). Eight additional clones were examined for bombesinlike immunoreactivity and none were markedly decreased (data not shown). It is possible that the altered growth properties and morphology may be associated with c-myc mRNA production and the biochemical properties are independent but at this time there is insufficient data to draw any firm conclusions.

This study shows that following transfection of the c-myc gene in a c-myc-neo construct into a parent SCLC cell line, H209, not expressing c-myc mRNA results in c-myc mRNA expression. This expression is associated with the altered cellular morphology, accelerated growth rates, and increased cloning efficiencies also observed in SCLC cell lines naturally expressing c-myc mRNA. These observations demonstrate that increased c-myc expression can cause altered growth properties and altered morphology in human SCLC.

\section{Acknowledgments}

We gratefully acknowledge Edward Russell for furnishing H209 Clone DD1 and for performing the L-dopa decarboxylase assays and Hunt Potter for his help in developing the electroporation technique. We would also like to express our gratitude to Tim Bender and Eric Seifter for the assistance with the $S_{1}$ nuclease analysis and Daniel Ihde and Edward Sausville for their editorial assistance.

\section{References}

1. Mougneau, E., L. Lemieux, M. Rassoulzadegan, and F. Cuzin. 1984. Biologic activities of v-myc and rearranged c-myc oncogenes in rat fibroblast cells in culture. Proc. Natl. Acad. Sci. USA. 81:5758-5762.

2. Land, H., L. F. Parada, and R. A. Weinberg. 1983. Tumorigenic conversion of primary embryo fibroblasts requires at least two cooperating oncogenes. Nature (Lond.). 304:596-602.

3. Keath, E. J., P. G. Caimi, and M. D. Cole. 1984. Fibroblast lines expressing activated c-myc oncogenes are tumorigenic in nude mice and syngeneic animals. Cell. 39:339-348.

4. Stewart, T. A., P. K. Pattengale, and P. Leder. 1984. Spontaneous mammary adenocarcinomas in transgenic mice that carry and express MTV/myc fusion genes. Cell. 38:627-637.

5. Campisi, J., H. E. Gray, A. B. Pardee, M. Dean, and G. E. Sonenshein. 1984. Cell-cycle control of c-myc but not c-ras expression is lost following chemical transformation. Cell. 36:241-247.

6. Armelin, H. A., M. C. S. Armelin, K. Kelly, T. Stewart, P. Leder, B. H. Cochran, and C. D. Stiles. 1984. Functional role for c-myc in mitogenic response to platelet-derived growth factor. Nature (Lond.). 310:655-660.

7. Kelly, K., B. H. Cochran, C. D. Stiles, and P. Leder. 1983. Cellspecific regulation of the c-myc gene by lymphocyte mitogens and plateletderived growth factor. Cell. 35:603-610.

8. Muller, R., R. Bravo, J. Burckhardt, and T. Curran. 1984. Induction of c-fos gene and protein by growth factors precedes activation of c-myc. Nature (Lond.). 312:716-720.

9. Makino, R., K. Hayashi, and T. Sugimura. 1984. C-myc transcript is induced in rat liver at a very early stage of regeneration or by cycloheximide treatment. Nature (Lond.). 310:697-698.

10. Goyette, M., C. J. Petropoulos, P. R. Shank, Fausto. 1984. Regulated transcription of c-Ki-ras and c-myc during compensatory growth of rat liver. Mol. Cell. Biol. 4:1493-1498.

11. Little, C. D., M. M. Nau, D. N. Carney, A. F. Gazdar, and J. D. Minna. 1983. Amplification and expression of the c-myc oncogene in human lung cancer cell lines. Nature (Lond.). 306:194-196.

12. Nau, M. M., D. N. Carney, J. Battey, B. E. Johnson, C. Little, A. Gazdar, and J. D. Minna. 1984. Curr. Top. Microbiol. Immunol. 113: 172-177.

13. Hann, S. R., and R. N. Eisenman. 1984. Proteins encoded by the human c-myc oncogene: differential expression in neoplastic cells. Mol. Cell. Biol. 4:2486-2497.

14. Cuttitta, F., D. N. Carney, J. Mulshine, T. W. Moody, J. Fedorko, A. Fischler, and J. D. Minna. 1985. Bombesin-like peptides can function as autocrine growth factors in human small-cell lung cancer. Nature (Lond.). 316:823-826.

15. Gazdar, A. F., D. N. Carney, M. M. Nau, and J. D. Minna. 1985. Characterization of variant subclasses of cell lines derived from small cell lung cancer having distinctive biochemical, morphological, and growth properties. Cancer Res. 45:2924-2930.

16. Carney, D. N., A. F. Gazdar, G. Bepler, J. G. Guccion, P. J. Marangos, T. Moody, M. H. Zweig, and J. D. Minna. 1985. Establishment and identification of small cell lung cancer cell lines having classic and variant features. Cancer Res. 45:2913-2923.

17. Carney, D. N., J. B. Mitchell, and T. J. Kinsella. 1983. In vitro radiation and chemotherapy sensitivity of establish human small cell lung cancer and its large cell morphologic variants. Cancer Res. 43:28062811.

18. Potter, H., L. Weir, and P. Leder. 1984. Enhancer-dependent expression of human kappa immunoglobulin genes introduced intop mouse pre-B lymphocytes by electroporation. Proc. Natl. Acad. Sci. USA. 81:7161-7165.

19. Zimmermann, U., and J. Vienken. 1982. Electric field-induced cell-to-cell fusion. J. Membr. Biol. 67:165-182.

20. Neumann, E., M. Schaefer-Ridder, Y. Wang, and P. H. Hofschneider. 1982. Gene transfer into mouse lyoma cell by electroporation in high electric fields. $E M B O J .1: 841-845$.

21. Chirgwin, J. M., A. E. Przybyla, R. J. McDonald, and W. J. Rutter. 1979. Isolation of biologically active ribonucleic acid from sources enriched in ribonuclease. Biochemistry. 18:5294-5299.

22. Hieter, P. A., G. F. Hollis, S. J. Korsmeyer, T. A. Waldman, and P. Leder. 1981. Clustered arrangement of immunoglobulin lambda constant regions in man. Nature (Lond.). 294:536-540.

23. Southern, E. M. 1975. Detection of specific sequences among DNA fragments separated by gel electrophoresis. J. Mol. Biol. 98:503517.

24. Gunning, P., P. Ponte, H. Okayama, J. Engel, H. Blau, and L. Kedes. 1983. Isolation and characterization of full-length cDNA clones for human alpha, beta, and gamma actin mRNAs: skeletal but not cytoplasmic actins have an amino-terminal cyteine that is subsequently removed. Mol. Cell. Biol. 3:787-795.

25. Battey, J., C. Moulding, R. Taub, W. Murphy, T. Stewart, H. Potter, G. Lenoir, and P. Leder. 1983. The human c-myc oncogene: structural consequences of translocation in the IgH locus in Burkitt lymphoma. Cell. 34:779-787.

26. Searle, S. R. 1971. Linear Models. John Wiley and Sons, Inc., New York.

27. Patterson, M. K., Jr. 1979. Measurement of growth and viability of cell in culture. In Methods in Enzymology, Vol. 58. W. Jakoby and I. H. Pastan, editors. Academic Press, Inc., New York. 141-152.

28. Baylin, S. B., M. D. Abeloff, G. Goodwin, D. N. Carney, and A. F. Gazdar. 1980. Activities of L-dopa decarboxylase and diamine 
oxidase (histaminase) in human lung cancers and decarboxylase as a marker for small (oat) cell cancer in cell culture. Cancer Res. 40:19901994.

29. McMahon, J. B., H. M. Schuller, A. F. Gazdar, and K. L. Becker. 1984. Influence of priming with 5-hydroxytryptophan on APUD characteristics in human small cell lung cancer cell lines. Lung. 162:261264.

30. Erikson, J., K. Nishikura, A. Rushidi, J. Finan, B. Emanuel, G. Lenoir, P. C. Nowell, and C. M. Croce. 1983. Translocation of an immunoglobulin $\mathrm{K}$ locus to a region 3 ' of an unrearranged c-myc oncogene enhances c-myc transcription. Proc. Natl. Acad. Sci. USA. 80:7581-7585.

31. Croce, C. M., W. Thierfelder, J. Erikson, K. Nishikura, J. Finan, G. M. Lenoir, and P. C. Nowell. 1983. Transcriptional activation of an unrearranged and untranslocated c-myc oncogene by translocation of a C lambda in Burkitt lymphoma cells. Proc. Natl. Acad. Sci. USA. 80: 6922-6926.
32. Nishikura, K., A. Rushdi, J. Erikson, R. Watt, G. Rovera, and C. Croce. 1984. Differential expression of the normal and of the translocated human c-myc oncogenes in B cells. Proc. Natl. Acad. Sci. USA. 80:4822-4826.

33. Taub, R., C. Moulding, J. Battey, W. Murphy, T. Vasicek, G. M. Lenoir, and P. Leder. 1984. Activation and somatic mutation of the translocated c-myc gene in Burkitt lymphoma cells. Cell. 36:339348.

34. Hollis, G. F., K. F. Mitchell, J. Battey, H. Potter, R. Taub, G. M. Lenoir, and P. Leder. 1984. A variant translocation places the lambda immunoglobulin gene $3^{\prime}$ to the c-myc oncogene in Burkitt's lymphoma. Nature (Lond.). 307:752-785.

35. Hann, S. R., H. D. Abrams, L. R. Rohrschneider, and R. N. Eisenman. 1983. Proteins encoded by v-myc and c-myc oncogenes: Identification and localization in acute leukemia virus transformants and bursal lymphoma cell lines. Cell. 34:789-796. 